\title{
Valuation Studies? Our Collective Two Cents
}

Hans Kjellberg*, Alexandre Mallard*, Diane-Laure Arjaliès, Patrik Aspers, Stefan Beljean, Alexandra Bidet, Alberto Corsin, Emmanuel Didier, Marion Fourcade, Susi Geiger, Klaus Hoeyer, Michèle Lamont, Donald MacKenzie, Bill Maurer, Jan Mouritsen, Ebba Sjögren, Kjell Tryggestad, François Vatin, and Steve Woolgar

\footnotetext{
Abstract

This article presents the results of a poll made among the members of the editorial and advisory boards of Valuation Studies. The purpose is to overview the topic that is the remit of the new journal. The poll focused on three questions:

1. Why is the study of valuation topical?

2. What specific issues related to valuation are the most pressing ones to explore?

3. What sites and methods would be interesting for studying valuation?

The answers to these questions provided by sixteen board members form the basis of the article. Based on these answers, it identifies a number of themes concerning the study of valuation, elaborating on the rationale for attending to valuation, the conceptual challenges linked to this, and the specific issues and sites that deserve further attention.

Key words: value as noun and verb; valuation processes; topicality of valuation; conceptual challenges; sites of valuation; research agenda

*Hans Kjellberg, Department of Marketing and Strategy, Stockbolm School of Economics, hans.kjellberg@hhs.se

*Alexandre Mallard, Centre de Sociologie de l'Innovation, Ecole des Mines ParisTech, alexandre.mallard@mines-paristech.fr

(C) 2013 The authors

LiU Electronic Press, DOI 10.3384/vs.2001-5992.131111

http://valuationstudies.liu.se
} 


\section{Valuation Studies}

\section{Introduction}

The launch of a scientific journal is an important moment. Historians teach us that new publications usually appear at key points in scientific practice: the identification of new objects and phenomena, the emergence of disciplines, the structuring of novel research fields, the development of specific methodologies and modes of enquiry, etc. We cannot, in the present context, speak for the two editors who have taken the initiative to create "Valuation Studies" but we can quite easily decipher two of their intuitions in the matter: first, the feeling that we are currently experiencing significant shifts in the valuation of various entities-objects, products and services, people, projects, organizations, etc.-in society; second, the perception that the underlying transformations are actively scrutinized by a number of scholars in a research field that is extremely broad, heterogeneous and interdisciplinary.

This research field involves sociologists, economists, marketers, STS (Science, Technology and Society) researchers, anthropologists, philosophers, semioticians, specialists in accounting or management science, and probably scholars of other scientific domains. All of them discuss and share a series of questions, hypotheses, agreements and disagreements, empirical results concerning the changing processes through which value and values come out. A number of emergent surveys and review papers, already available, enable us to grasp the extent of this field and suggest possibilities for ordering the abundant research that it hosts (see for instance Beckert and Aspers 2011; Adkins and Lury 2011; Lamont 2012). On the occasion of the publication of its first issue, Valuation Studies wishes to propose its own contribution to the task of delineating and marking out this research landscape.

For this, we have opted for a simple method, based on two principles: on the one hand, we decided to build on the knowledge and skills of the journal's own experts, i.e. the advisory and editorial boards' members, who largely display the variety of contemporary analytic standpoints towards valuation processes; on the other hand, we mobilized a very light protocol and equipment, so as to obtain a quick and schematic idea of the stakes and research issues at play. Thus, we have invited the board members to answer briefly three questions:

1. Why is the study of valuation topical?

2. What specific issues related to valuation are the most pressing ones to explore?

3. What sites and methods would be interesting for studying valuation?

Sixteen board members kindly took time to answer our request, provided a couple of sentences or paragraphs in response to each 
question, and accepted to be listed as secondary authors of this article. Hence, it should be clear to the reader that although the "we" used in this text refers to the two first authors, who organized the poll and analyzed the results, this article is a collective achievement, based on the active contribution of all the respondents. The collection of short texts that we gathered this way constitutes a quite unusual empirical material. It is obviously not suited to mapping thoroughly a research field, as one usually tries to do when writing a literature review. However, it offers a series of viewpoints and prospective attitudes on the issues posed by the transformation of valuation processes, so as they can be apprehended from each contributor's position in the research field. In a sense, we have gathered a set of snapshots taken in this field along particular angles, showing situated conceptual objects of interest and concrete pieces of reality, and pointing to specific vantage points. This paper is an attempt to organize and synthesize the content of this material and to provide a picture, even if a multiple one, of the territory circumscribed by the study of valuation practices. Our ambition is not to draw a detailed map based on these snapshots. The aim is rather to sketch borders, to qualify the relief and catch sight of the uneven grounds, to detect already existing avenues and to identify some possible new ones. We are inviting the reader to follow us in this exploratory exercise.

\section{Reasons for Studying Valuation}

Our first poll question concerned the topicality of valuation studies. What are the reasons for researchers from different fields to engage with questions about valuation and worth? In compiling the answers provided by the board members, we identified four main lines of argument. The remainder of the section is structured according to these, starting with the most common type and ending with the least common one.

\section{Because It Is Empirically Relevant/Important}

By far the most common answer to the question of topicality was anchored in observational statements about the state of the world. Our conclusion is that questions about valuation are generally perceived to be of considerable and/or growing interest in society at large. Within this category there was variation between answers that were general and sweeping and others that concerned specific empirical contexts. There was also variation among the respondents in terms of the specific observations called on, often related to their disciplinary home and general research interests.

According to some of the contributors, macro-level trends underlie current changes concerning the ways in which value and values are produced and transformed: such factors as neoliberalism, the rise of 


\section{Valuation Studies}

new public management, the spread of meritocracy, consumerism or ICT development are evoked, in a more or less diffuse way, in several of the responses. The most obvious domain where this relation between valuation and macro-social change is empirically expressed is finance: Donald MacKenzie recalled the laborious search for stable and robust values that we are witnessing in the current credit and Eurozone crises. But even when valuation issues don't give birth to such spectacular globalized concerns, their topicality can be linked to developments at the societal level. The idea that the current period experiences changes and controversies in the practices of valuation was raised by several of the board members, even if this idea is tackled from diverse angles.

Emmanuel Didier pointed to the evolution and even, to some extent, to the extinction, of the bourgeois regime of values, changing for instance the nature of what is publicly valued in society. Ebba Sjögren saw a proliferation of values in the contemporary period, triggering contestations of the particular dominant models of valuation. Klaus Hoeyer expressed another concern, that of the ever growing role of technical systems and complex metrologies in the characterization of value, for instance in the healthcare domain where large and powerful information systems are used to define and measure the quality and performance of services. In a similar vein, Bill Maurer pointed to the rise of "big data" infrastructure, changing the transactional regime and architecture of value creation and circulation. In a period where the conventional warrants of value-labour, the state, the market, etc.-would experience a reconfiguration of their relations, these would lead to planetary realignments in the channels of valuation.

Steve Woolgar evoked the proliferation of web based rating systems, a category of devices that derive from traditional instruments of valuation in the political and organizational context (appraisal and comparison of value for money) but that have expanded to support claims about the emancipation and democratization of practices in the online realm. Patrik Aspers perceived in the contemporary period an erosion of the traditional standards supporting evaluation, and the rise of arenas where valuation processes tend to integrate new aesthetic dimensions.

\section{Because It Is Theoretically Challenging/Interesting}

The second most common type of motive for the topicality of valuation had theoretical roots. Board members argue that there are problems with currently dominant theoretical approaches to the issue of valuation. The way in which economic models conceive of value is seen as particularly troublesome, but other models are also evoked, e.g. from sociology and marketing. 
Diane-Laure Arjaliès pointed to the paradox that academics and experts in various domains search for "objective" and "performance generative" assessment tools despite the fact that it is widely acknowledged that valuations are socially constructed. Financial markets might be a case in point here. A refined theoretical understanding of the issues at stake should doubtlessly help reconcile this tension, notably through a better attention to the dynamic and processual nature of valuation, as opposed to a static conception considering mainly the implementation of already given sets of values -a point that we will return to below.

Susi Geiger observed the theoretical status-quo at stake in the interdisciplinary space bounded by economics and marketing: the dominant traditional economic view, according to which price is the main regime of valuation, has been somehow adopted by marketing research, leading to the idea that differences in value can be expressed in monetary numbers even when they imply psychological perceptions. Geiger called for a shift in this perspective, and for a new conception of the valuation processes: instead of assuming that all expressions of value can be translated into a common metric, it should account for the collective, non linear, multi-dimensional character of valuation processes, and refuse to reduce them either to price or power.

François Vatin proposed another formulation of the theoretical puzzle at stake. According to him, the Walrassian revolution in economics has led to a sort of Yalta in the reflection on valuation: on the one hand, moral and philosophical approaches have dealt with values without measurement; on the other hand, management science and economics approaches have provided mathematic tools for measuring value in organizations and markets. To this scenario, that recalls David Stark's description of "Parsons' pact" (Stark 2009), Vatin added that the failure of general equilibrium theories has helped to bring sociology back in the debate on measured values, and that a current theoretical challenge is to articulate better the analysis of moral values and economic value.

These are three examples of specific theoretical challenges that research on valuation should meet. At this stage, the way in which such challenges should be made compatible and articulated remains an open question. Let us notice, however, that some of the respondents adopt an ambitious stance towards the question of theory building: in their collective response, Stefan Beljean and Michele Lamont stressed theory development as one of the more pressing issues, arguing for the need "to go beyond a mere accumulation of case studies and follow a more ambitious and cumulative approach to theory building." Moving to a higher degree of abstraction so as to identify similarities and differences across studies would enable us to provide a comprehensive picture of valuation processes. 


\section{Because It Allows Us to Do Interesting or Fun Stuff}

The third argument, which links to the previous one, could be said to concern affordances in the sense of entities that lend themselves to certain uses. These arguments were not primarily framed in terms of shortcomings in existing theoretical edifices, but rather more hands-on in recognizing that by using new theoretical tools or by assuming a different vantage point (e.g. attending to the process of valuation) new areas of investigation had opened up. This is a little like the situation described by Shove and Araujo (2010) where a man who had newly acquired an angle grinder suddenly found himself looking for things to grind!

While valuation appears to be a general concern in several disciplinary areas, some respondents argued that new conceptual approaches and analytical moves have the potential to revitalize its study. The exploration of new possible alliances between pragmatism and theoretical approaches to which it is traditionally opposedsemiotics, statistics, epistemology, phenomenology...-could for instance shed new light on valuation processes.

Alberto Corsin saw several opportunities in the notion of valuation to explore conceptual areas as well as practical fields of investigation. As world-making and sense-making activities, valuation processes partake in the ontological practices through which human and nonhuman entities make room for themselves in their environments. They constitute an invitation to rethink the currencies of art-science cooperation, or to study novel experiments in democratic, political, urban assemblage and "cosmopolitics".

\section{Because We Can Improve the World}

The fourth and final type of argument for the topicality of valuation had a distinctly different flavour. In a nutshell it suggested that research on valuation could contribute or promised to improve the world. The argument was explicitly visible in a couple of answers, but implicitly present in a few more.

Kjell Tryggestad offered one example of a direct connection between valuation research and its application for political or industrial purposes. He suggested the elaboration of theoretical and methodological perspectives supporting the valuation of projects beyond the mere application of traditional economic tools and routines as one important challenge. In areas like the construction and engineering industries, the project, which constitutes the basic form of organization and coordination, is still valued in reference to standard concepts like price/cost or assets/liability. Such projects deliver major infrastructures of contemporary life like housing, circulation, healthcare institutions, etc., many of which play a crucial role in determining the sustainable performance of our predominant mode of co-existence, the city. Consequently, there is a need for more 
multidimensional, more dynamic, more comprehensive methods and metrics to apprehend their characteristics. A clear contribution of research in this domain would be to inform the decision-making processes at play in the context of design, production or commercialization.

Another way to apprehend the concrete impact of research on valuation is to be found in the critique of the dominant model at work in this conceptual area-clearly the economic one-or in unveiling the invisible or hidden realities lying in the routine and non-creative application of existing norms and procedures to the various situations that pose new concerns on value and values. This is what one can read in Hoeyer's statement that academic research can contribute to "unpacking the implicit normative assumptions" that become blackboxed in diverse technical infrastructures.

Beyond any explicit proposition to generate policy recommendation, the importance of the practical impacts of research on valuation can be identified in a more diffuse way in many contributions: it is present behind a perceptible broad worry concerning the valuable activities that can be legitimately pursued, behind the curiosity of knowing the value-and not only the price-of many things, behind the necessity to struggle against the inequalities that result from the contemporary changing orders of values.

\section{What Do We Mean by Valuation?}

As a matter of fact, this plurality of concerns for the topicality of valuation accordingly hides a plurality of definitions of what is valuation. While the poll did not specifically ask the board members to define valuation or discuss how they conceived of terms such as value, worth, valuing, evaluation, etc., their answers nonetheless allow us to point out a few things about this conceptual landscape. Below, we offer a few observations concerning conceptual challenges linked to the study of valuation raised by the responses to the poll, without any ambition of completeness, or even coherence.

Starting with the very concept of valuation, a couple of our board members were kind enough to offer tentative definitions. For instance, Patrik Aspers suggested valuation could be viewed as the process of "bringing order to mere 'differences"". On a similar note, Ebba Sjögren suggested that valuation concerned "how people, things and idea(l)s are ordered in relation to one another". The connection to order(ing) figuring in both these remarks suggests that valuation is intimately related to classification. This made us recall Bowker's and Star's $(1999,1)$ quip "to classify is human", as well as their definition of classification as "a spatial, temporal, or spatio-temporal segmentation of the world" (ibid., 10). 
However, as Diane-Laure Arjaliès emphasized, valuation aims to signify the world rather than accurately account for it. Possibly, this complicates its relation to classification. Although one could argue that signification is central also to many if not most classification efforts, the reasoning nonetheless provides an argument that classification and valuation is not precisely the same thing. One way of recognizing the link between the two while retaining a distinction is to imagine valuation and classification as ordering activities in which the relative emphasis on signification and representation differs (see Figure 1). Classification in its pure form would then be an ordering that emphasizes representation over signification, while valuation would do the opposite. Whether this introduces yet a layer of complexity to the study of valuation, or in fact simplifies matters, is debatable. Nonetheless, as Arjaliès pointed out, the role of signification in valuations suggests that the meaning of valuation is not to be found in the object to which it refers, but in how that object is being referred to.

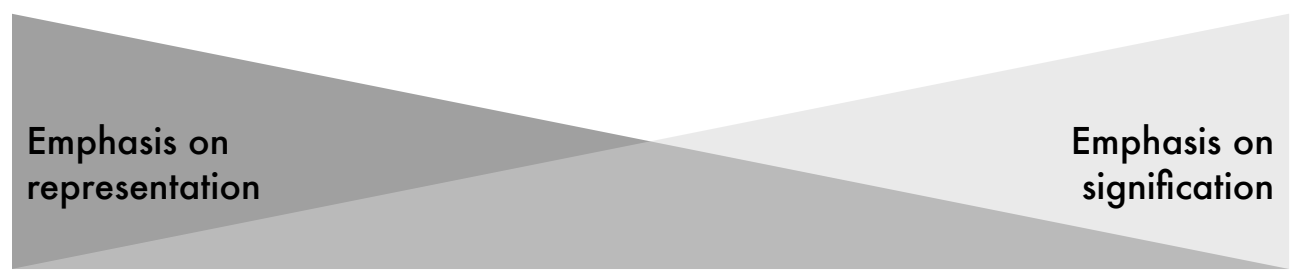

Classifications

Valuations

Figure 1. Valuation and classification as ordering practices with different emphases.

The latter point provides a link to another important conceptual issue that figured in several of the responses, but nowhere as clearly as in Jan Mouritsen's contribution. Valuation, he argued, is related both to the noun value (as in there being things that are values, and objects that have value) and the verb value (as in things being the objects of certain activities-being valued). This dual, noun-verb character of valuation-emphasized already by Dewey (1939)—could be found in many of the responses to the poll. We have chosen to structure the remainder of the section according to this duality, but also discuss issues that concern the interrelation between value as noun and value as verb.

\section{Value as Noun}

In discussing value as noun, several board members emphasized the existence of multiple values, often as a way of throwing the notion of economic value in relief. Several of these remarks recall Parsons' pact (Stark 2009) and the classic distinction between value (singular) as the 
outcome of an individual valuation effort, and values (plural) as the standards, rules, norms or ideals used to perform such valuations (Taylor 1961; Holbrook 1999).

In terms of value (singular), the dominance of economic value in contemporary society was something that both fascinated and bothered the respondents. The fascination mainly concerned how different values (plural) were being translated, aligned, or co-ordinated into one value (singular). Several contributors called for increased conceptual precision on this, including Kjell Tryggestad who pointed at the prioritization of economic/financial methods and metrics in the valuation of projects. Donald MacKenzie raised a more specific issue related to economic valuation, namely how valuations relate to prices, which is of central importance in the financial markets. In a more critical vein some respondents objected to conceptual approaches to valuation that simply assume that different values are reducible to a single measure (notably in the fields of economics and marketing). In this connection it can be useful to recall, as some respondents did, that there are also different conceptions of value (singular), including notions such as exchange value, use value, and semantic value (we could also add the labour theory of value to this list).

Related to the above, but more clearly linked to values (plural), many of the respondents emphasized the need to conceptualize the existence of multiple values. Here, Susi Geiger provided another take on the link between value and price, raised above by MacKenzie, arguing for the need to "explore those aspects of value that cannot readily be translated into price". Of course, discussions about the relation between value and price become particularly interesting if we adopt the idea that valuation aims to signify the world, and that it thus revolves around a process of investing various elements with meanings. Based on this, Arjaliès argued for the need to "explore the disputability and multiplicity of value regimes", a theme that recalls, but moves beyond the different forms of worth examined by Boltanski and Thévenot ([1991] 2006).

Another critical line of argument concerning the multiplicity of values revolved around the emergence of increasingly powerful valuation regimes that affirm certain values over others. Indeed, as Marion Fourcade noted, the very concept of valuation is strongly associated with the process of attaching economic value to some object. In contrast, the term worth is broader and can be used for nonmonetary registers as well. In this connection, Klaus Hoeyer emphasized the risks associated with black-boxing the process of ascribing value (singular) given the dominance of certain values (plural) over others in technical systems of evaluation. Consequently, the multiplicity of values that may or may not enter into the determination of value provides one reason to address the notion of value as verb (see below). 
Another argument for a process view, raised by several respondents, concerned the poverty of conceptualizations that considered only given values (plural). Emmanuel Didier stressed that values-things that have worth-change and that we need to address the process through which such changes take place, while Aspers argued that standards of evaluation have gradually eroded in society thus putting greater emphasis on the process of valuation. Alexandra Bidet, finally, argued against approaches that "only consider already given sets of values or principles of worth and use them as explanatory entities, or black-box the meaning of behaviours and attitudes instead of exploring their normative creativity." There are thus several links to our next subsection and the issue of value as verb.

\section{Value as Verb-the Valuation Process}

We should make clear at the outset that the verb/process perspective on valuation implied by value as verb, figured very prominently in the responses to our poll. Indeed, some board members seem to equate the notion of valuation with a process perspective; a move away from "units of value" to "world-making and sense-making practices", as Alberto Corsin put it. Besides responding to the concerns above about considering values as given and failing to elucidate how certain values come to carry more weight than others, he underscored the affordance of localized accounts of valuing in specific contexts as another merit of a process focus.

Several contributors proposed more fine-grained/precise conceptualizations of the valuation process. First, Beljean and Lamont argued for a distinction between valuation (the process of giving worth) and evaluation (the process of assessing). This echoes Francois Vatin's distinction between valorizing (production of value) and evaluating (assessment of value) (see also the article by Vatin in this issue of VS). Second, Arjaliès and Bidet both suggested a need to go beyond these processes and to consider the very genesis of orders of worth/value regimes, borrowing from the pragmatist perspective. Bidet linked this process to experience, to the inquiry on what our interests and desires are and should be, an inquiry that creates meaning in the sense that it changes the way we are intertwined with the world. Third, Bill Maurer highlighted another facet of the valuation process by questioning the extent to which values can travel. Do the various arrangements put in place to channel value ("carriers of value") also contribute to constitute value? A fourth challenge raised, concerned how to conceptually handle the linking of different values. This issue is relevant at the level of individual valuation (systems), but as Sjögren noted, also involves the issue of contestations and conflicts between different sites of valuation. Understanding this type of process, the centrality of which some contributors attribute to the need for 
collective/intersubjective agreements on matters of valuation, emerges as one central conceptual challenge in the study of valuation.

A final facet of the valuation process, raised most clearly by Steve Woolgar and Jan Mouritsen, concerns its procedural facet. In linking valuation to current accountability and audit regimes, e.g. the need to show that you are getting value for money, they both question whether valuation needs to follow certain procedural rules to be effective. Such observations raise further questions not only about how valuation procedures are put in place and the quality of the output they produce, but also about their wider import on our lives in the sense of what they make us do. On a related but perhaps slightly more optimistic note, Corsin emphasized how valuations also offer new action alternatives, providing ways in which actors can "make room for themselves". To some extent, these notes also invite us to shift from theoretical concerns to engagements with what we see.

\section{Studying Valuation-What, Where and How?}

This section is likely to be instructive at least as far as prospective authors of Valuation Studies are concerned. In a sense, what we are offering here is a compilation of issues and associated empirical fields that the advisory and editorial boards consider pressing and would like to see research on. While the poll questions specifically asked the respondents to elaborate on both pressing issues to address (Q2) and specific sites/methods for studying valuation (Q3), the responses we received indicated to us that these questions were closely intertwined. We will first report on the issues that the board members raised, and then move on to discuss their comments regarding sites, before discussing the interrelation between the two. We will finally make some observations concerning the question of methods.

\section{What Issues Are Worth Examining?}

As will become clear, we have already introduced in the preceding sections many of the issues judged as important by the board members. Looking at the process aspect of valuation (which, as we noted above, dominated the responses) with a more thematic lens, it seemed possible to identify three main questions. The first revolves around the relations between diverse forms of valuation; the second tackles the organization and technical dimension of valuation processes; the third deals with the political dimension of valuation, and its relation with democracy.

How are valuation processes interrelated? In a way, one of the consequences of shifting the analytical perspective from value/values to valuation is that it enables-or obliges-us to address the question of the relations between a plurality of practices and processes. Boltanski and Thevenot ([1991] 2006) once justified their preference for worth 
over values in a similar way: they argued that while the theories of values would generally recognize the existence of innumerable and incommensurable potential qualifications of the same object or situation, potentially leading to unbridled relativism, the economy of worth would focus on a limited set of reference principles linked by a specific architecture of mutual relations. The interest for valuation leads us to make a similar move: although it doesn't aim at establishing a general framework-a "grammar of worth", so to speak, as in the model proposed by Boltanski and Thevenot-it requires to go beyond the mere observation of a plurality of valuation processes and to actively deal with their interrelations.

When are the outcomes of different valuations competing and when do they lead to substitutions? Do their relations involve causal processes - for instance when a given valuation would lead to another one or would require another one to be present? When are they unrelated and when can they co-exist in a space without any mutuality apart from temporal and spatial co-presence? These questions go through the responses to the poll given by Mouritsen, Sjögren, Geiger and many others. Aspers phrased the stake a bit differently, proposing to investigate how valuation relates to other forms of co-ordination, while others were specifically concerned with the links between use values, economic values and semantic value. Notice however that dealing with the issue of plurality and interrelations requires to take into account a relative asymmetry: as Fourcade recalled, due to its specific relation with value, and not only values, economic valuation very often occupies a particular place in the network of relations linking the various processes. Although it can be tackled in different ways, it seems difficult to ignore this particular asymmetry.

What are the organizational and technological supports of valuation? Here again, the importance of the question originates in the shift from value/values to valuation. Since we are no longer talking about static realities but about dynamic processes, the modalities of enactment of these processes become an inevitable focus of inquiry. Further, as we distance ourselves from a perspective where these processes would result from a pure logic of emergence, making value miraculously appear from the interaction of unconnected actors, we have to investigate the concrete web of rules, instruments, routines, and devices engaged in valuation. How do actors set up the collective socio-technical agencements that make valuation possible, stable, credible, accountable, and liable to compete with alternative perspectives on value? No less than half of the responses in some way touched upon the role of arrangements/metrics/socio-technical devices/ infrastructures in the process of ascribing value (singular) to entities or behaviours.

Sjögren stressed the necessity to investigate how valuing arrangements are created and maintained, how different sites of valuation are 
interrelated and what role "mundane technologies" play in this system. A related issue, well worth examining, is the relations between everyday and more formalized, institutionalized forms of evaluation. Tryggestad recalled the complex organizational and technological nexus that constitute large projects and infrastructural activities, a nexus within which valuation processes might, in a sense, be embedded. The possibility of human intervention in and accountability for valuation processes engaging more and more technology is also a concern raised by several contributors. MacKenzie and Arjaliès mentioned the role of automated trading systems like high frequency trading as technologies that are still quite controversial: they are sometimes praised not only for their capacity to accelerate transactions but also for their propensity to avoid human intervention in certain parts of the valuation processes. Hoeyer suggested that automated valuations are similarly present in healthcare settings, where complex technical systems control resource allocations and implicitly or explicitly ascribe monetary values to treatments, lives and sometimes even body parts. Finally, as we noted above, several responses highlighted the extent to which socio-technical systems may hide the fact that specific values (plural) are being prioritized. In this connection, Beljean and Lamont suggested that the mobilization of evaluative devices "contribute to objectifying or institutionalizing interpersonal agreement (Karpik 2010).”

How does valuation contribute to the construction of democracy (or more modestly, to the realization of various democratic values)? Here again, a possible way to put this issue into perspective is to contrast the current situation with traditional debates mobilizing the dichotomy value/values. Besides being a point of crystallization of the debate between academics of various disciplinary denominations, the opposition between value and values is also a classic rhetoric figure in the democratic debate: economic freedom of initiative is meant to help create value whereas welfare intervention is supposed to secure such values as equity, justice or diversity in the construction of society. A focus on valuation (processes) does not do away with the democratic debate and reflection, but it should lead us to move away from the traditional format of this discussion. Attention to valuation does not require the staging of a dualist conflict between economy and politics but encourages us to investigate the plurality of conceptions of value/ values that lies in a variety of social spheres. Here, we should not forget that democracy may also have its own conflicting plurality of values. In a sense, the question that the issue of valuation raises concerning democracy is not only that of the government of the economy: it refers in a much broader way to the inscription in the democratic regime of dynamic processes contributing to the construction of possible, and sometimes conflicting, social orders in a variety of situations. 


\section{Valuation Studies}

The responses to our poll provide various illustrations and suggest possible avenues for research here. Arjaliès proposed to inquire on what we desire and hold precious and she suggests that making public, debatable and revisable these valuations is a way to contribute to the democratization of institutions. Research on valuation could help elucidate the extent to which innovative valuation processes contribute to citizen participation, as might be the case with rating systems of various sort (Woolgar) - or in a very different context, to elucidate how valuation processes support the development of nonrepresentational forms of collective actions endowed with their own specific 'cosmopolitics', like in the Occupy movement (Corsin). Several contributors noted the interest of examining how changing frames of reference concerning values can lead to new social inequalities or new distributions of power (Didier, Geiger and others). Beljean and Lamont suggested that social and policy relevance should guide the choice of empirical fields to investigate: according to them, situations involving high stakes for individuals and social groups (stigmatized groups, low-income population, downwardly mobile occupational groups, etc.) should be preferred over the traditional niche markets on which much value research has focused.

\section{Where and How to Study Them}

The sites and methods proposed for studying valuation are not independent of the issues proposed by the contributors above. Nonetheless, we will in this section simply present the proposed sites, in the form of an emerging typology. The subsequent section will then seek to link issues and sites.

A first set of sites could be characterized as highly economized (Çaliskan and Callon, 2009; Çaliskan and Callon, 2010). This group includes various kinds of financial markets, or flow markets to speak with Knorr-Cetina (2006), but also commodity markets where physical products are exchanged under highly standardized conditions. Financial accounting and analysis also belong to this group of sitesinvolving highly standardized economic valuations-but differ from the financial and commodity markets in how they are organized. Indeed, the interrelation of these two types of economized sites constitutes an interesting site in its own right. Two strong arguments for studying these sites are that they revolve around (particular types of) valuation and that they are too important in contemporary society to be left unattended. Another argument is of course that some of these sites are subject to strains that to a considerable extent can be attributed to the kinds of valuations they produce (Sjögren, Arjaliès, MacKenzie, Fourcade).

A second group of sites could be characterized as complex and/or rapidly changing valuation situations. Here we find "hot" market situations in which the current valuation regime is being questioned or 
where such a regime has yet to be established, including for instance ecologically/morally/politically concerned markets. These sites engage conflicting conceptions of value and they often prompt open discussion about value systems (Geiger, Fourcade). Another type of sites in this category is large infrastructure projects, both because their valuation exhibits complexity and because they engage the evolution of important societal concerns (Tryggestad). As should be clear, this group of sites could include highly economized ones, with the important addition that this economization is being questioned.

A third group of sites could be characterized as sites of construction and reification of valuing systems, tools and organizations. This category would include technical and knowledge regulatory agencies, for instance in the healthcare sector, because these contribute to the shaping or reification of value systems (Hoeyer). Sites occupied with the construction and/or subsequent enforcement of accounting conventions would be another example (Sjögren, Arjaliès, Vatin). The construction and deployment of rating systems for various types of feedback (customer, supplier, expert, etc.) is yet another example of this type of site (Woolgar). A final example could be organizations that produce statistics, including both national statistics offices and market research agencies, because of their contribution to valuations (Didier).

The fourth and final type of sites proposed in the poll could be characterized as sites of social change. This type would include the rise of active political movements as well as the silent re-ordering of social groups. Specific examples of this type of site include: places where social movement and change occur, like social media, indigenous and Occupy movements (Corsin); politically and socially relevant places where social and political stakes are at play (Beljean and Lamont); studying emerging social elites since their emergence typically is linked to new values that are being embraced in society (Didier); studying mundane settings like workplaces and streets, sites that are critical for democracy in routinely provoking encounters between strangers (Bidet).

As a final remark concerning sites, we want to highlight that a couple of our respondents argued that valuation could be studied anywhere in society. Hence, they did not suggest any particular sites as more interesting than others. We interpret this as an encouragement for future contributors to VS to explore situations beyond those suggested in the proposed typology.

\section{Combining Issues and Sites/Methods}

In compiling and thinking through the responses presented in the previous two sections, we devised a tentative sorting grid based on the two dimensions of sites and issues. This provided us with an admittedly rough, yet productive framework (see Table 1) for 


\section{Valuation Studies}

discussing some questions and stakes that come out of our exercise at a prospective level.

Table 1. Specific objects of interests/challenges emerging from the combination of issues and sites for studying valuation.

\begin{tabular}{|c|c|c|c|}
\hline & $\begin{array}{c}\text { Relations between } \\
\text { valuations }\end{array}$ & $\begin{array}{l}\text { Technology and } \\
\text { organization }\end{array}$ & $\begin{array}{l}\text { Relation to } \\
\text { democratic } \\
\text { process }\end{array}$ \\
\hline $\begin{array}{l}\text { Highly } \\
\text { economized sites }\end{array}$ & $\begin{array}{l}\text { How to deal with } \\
\text { the structural } \\
\text { asymmetry } \\
\text { between economic } \\
\text { and other forms } \\
\text { of valuation? }\end{array}$ & $\begin{array}{l}\text { How is valuation } \\
\text { entangled in the } \\
\text { organizational } \\
\text { and technological } \\
\text { processes of } \\
\text { economic } \\
\text { exchange? }\end{array}$ & $\begin{array}{l}\text { How to mobilize } \\
\text { valuation in the } \\
\text { confrontation and } \\
\text { cooperation of } \\
\text { political and } \\
\text { economic orders? }\end{array}$ \\
\hline $\begin{array}{l}\text { Complex and/or } \\
\text { rapidly changing } \\
\text { valuation } \\
\text { situations }\end{array}$ & $\begin{array}{l}\text { Examining } \\
\text { mechanisms of } \\
\text { combination, } \\
\text { prioritization, } \\
\text { selection, and/or } \\
\text { extinction of } \\
\text { values. }\end{array}$ & $\begin{array}{l}\text { How organization } \\
\text { and technology } \\
\text { act as levers or } \\
\text { impediments in } \\
\text { the } \\
\text { reconfiguration of } \\
\text { value systems. }\end{array}$ & $\begin{array}{l}\text { How control is } \\
\text { exercised over the } \\
\text { inscription of } \\
\text { emerging } \\
\text { valuation schemes } \\
\text { in democracy. }\end{array}$ \\
\hline $\begin{array}{l}\text { Construction and } \\
\text { reification of } \\
\text { valuing systems, } \\
\text { tools and } \\
\text { organizations }\end{array}$ & $\begin{array}{l}\text { Unpacking the } \\
\text { mechanisms that } \\
\text { lead to the } \\
\text { reinforcement of } \\
\text { particular } \\
\text { valuations. }\end{array}$ & $\begin{array}{l}\text { Questioning how } \\
\text { valuation } \\
\text { processes become } \\
\text { (or fail to become) } \\
\text { efficient, } \\
\text { productive, } \\
\text { reliable. }\end{array}$ & $\begin{array}{l}\text { How to keep } \\
\text { valuation } \\
\text { debatable and } \\
\text { open to change } \\
\text { while allowing for } \\
\text { accountability and } \\
\text { consistency? }\end{array}$ \\
\hline $\begin{array}{l}\text { Sites of social } \\
\text { change }\end{array}$ & $\begin{array}{l}\text { Understanding } \\
\text { and challenging } \\
\text { the } \\
\text { transformation of } \\
\text { value systems } \\
\text { underlying social } \\
\text { change. }\end{array}$ & $\begin{array}{l}\text { How } \\
\text { organizational } \\
\text { and technological } \\
\text { resources of } \\
\text { valuation relate to } \\
\text { emerging social } \\
\text { orders? }\end{array}$ & $\begin{array}{l}\text { How to mobilize } \\
\text { valuation in the } \\
\text { democratic } \\
\text { government of } \\
\text { social change? }\end{array}$ \\
\hline
\end{tabular}


Highly economized sites (site 1) are sites where objects circulating in social space are constituted as goods endowed with a value defined as exchange value. From the point of view of the relations between valuations (issue 1) these sites would lead us to study the conditions of emergence, construction and negotiations of alternative conceptions of value under such asymmetric conditions. They offer the interesting feature that the valuation devices are inscribed-embedded, entangled -in the socio-technical networks of exchange themselves, which probably provides particular technological and organizational stakes (issue 2). As far as the inscription of valuation in democracy is concerned, one may encounter here the traditional problem of the compromises and negotiations that can make exchange value compatible with political orders (issue 3).

Complex and rapidly changing valuation situations (site 2) are sites where the question of the relations between valuations (issue 1) refers to the processes of prioritization, combination, hybridization, selection, etc. In these contexts, the transformation of the resources supporting the qualifying, ordering, quantifying, comparing of entities involve dynamic technological and organizational mechanisms: inertia of infrastructures, path dependency, flexibility, adaptive processes, etc. (issue 2). In terms of the issue of democracy (issue 3), one important question concerns the control of these dynamic mechanisms, from the point of view of the legitimacy of the normative principles that should be enforced in the transformative process, and from the point of view of the means to mobilize in order to achieve this goal.

Studying the construction and reification of valuing systems, tools and organizations (site 3 ) seems to offer a possibility to unpack specific relations (of dominance, balance, conflict, etc.) that have been, or are being forged between different valuations (issue 1). It would also allow inquiries into the role of specific technologies and forms of organizing in performing valuations, maybe offering a possibility to discuss questions about their efficiency and reach (issue 2). These sites would finally allow us to ask questions about possible conflicts with democratic processes, e.g. while things need to be debatable and open to change in democratic processes, this is not necessarily a quality that is nurtured in the construction of valuing systems (issue 3).

Studying valuation in sites of social change, finally, would allow us to examine, and maybe also to discuss, the alternative options between contrasted systems of values that are at stake in the transformation of collective life (issue 1). It would further offer possibilities to inquire into the architecture of shifting valuations, including how such shifts are organized and how existing technologies of valuation may contribute to or impede social change. Finally, such sites would take us to the heart of the issue of valuation in democratic processes (issue 3), opening up for inquiries into the role of valuation processes in the practical performance of democracy. 


\section{A Note on Methods}

The second part of our final question brought up the issue of methods. There is one very clear tendency in the comments received on this: as a group the board members propose a wide variety of different qualitative methods and approaches that could generate important results regarding the issues they outline. These included, but were not limited to; case studies, ethnographic methods, participant observation, comparative and mixed methods, etc. Some respondents explicitly said that any method could be used, making us recall the slogan "anything goes" (Feyerabend [1975] 1993). However, very strikingly, none of the respondents called for any kind of quantitative approach. Even when studying the construction of value through quantitative devices, the recommendations tended to be to 'draw on qualitative methods to study the quantitative'. One reason for this omission can perhaps be found in the conceptual link made between valuation and ordering/classification (see section 2). Based on this link, the kind of classifications necessary for the use of quantitative approaches are perhaps perceived as being too invasive into the very subject matter at hand. While this is certainly an important caveat, we cannot refrain from asking if we should not also be thinking about possible quantitative methods that could be used for studying issues related to valuation? If we are allowed to put forward a suggestion of our own it would be to see efforts within this journal to encourage the development of new and imaginative uses of quantitative methods for the study of valuation processes.

\section{Concluding Comment}

In their comments to our first draft, the editors asked us to provide a short concluding section "where you reflect on the coherence as well as diversity of themes". This is both an interesting and challenging task. We started this project by inviting members of the editorial and review boards to engage in valuation, provoking responses to our poll questions. Our attempted ordering of these responses similarly represents a valuation of their views. Finally, we have now invited readers of this text to engage in their own process of valuation. Such observations of valuations of valuations of valuations are likely to be common across valuation studies. This challenge of infinite regress emphasizes the centrality of recognizing our own participation in the phenomenon we study. Seeking to understand valuation is to engage in a continuous task of exploring what keeps ourselves as well as the systems we study going.

Taking a step back from our own valuation process, we noted two things. On the one hand, our collective two cents are not very easy to add up; the light protocol and equipment that we decided to employ for this exercise was never intended to render such an adding up 
possible. Perhaps that is a lesson in itself concerning processes of valuation. On the other hand, the responses provided by the board members did allow us to generate/suggest a number of currencies that appear to have purchase across individual members of this collective. That, too, carries a lesson regarding valuation.

Finally, the editors suggested that we "invite readers to contribute to the conversation by submitting pieces that further charts the terrains sketched, as well as challenges this very sketch.” In the spirit of our approach, we have chosen to end by doing precisely that.

Acknowledgments and disclaimer. The "poll-article" is a genre that neither of the main authors has ever tried before. Given this, we want to make the following remarks: The text was written by Hans Kjellberg and Alexandre Mallard, but draws extensively on the responses we received to the poll sent to the members of the editorial and advisory boards of Valuation Studies. We circulated a draft version of the article to the editors of Valuation Studies and received useful comments that allowed us to make improvements. A second draft was then circulated to all respondents of the initial poll, asking for further comments and also for their approval to use their contributions to the poll in the manner we had outlined. This allowed us to further polish on some of the arguments, and also gave us license to publish the text. To conclude: although this text was inspired by and indeed would have been impossible to write but for the contributions of our fellow board members, as the authors of the final text we assume full responsibility for any shortcomings and errors.

\section{References}

Adkins, Lisa, and Celia Lury, eds. 2012. Measure and Value. Malden, MA: Wiley-Blackwell / The Sociological Review.

Boltanski, Luc, and Laurent Thévenot. (1991) 2006. On Justification: Economies of Worth. Princeton: Princeton University Press.

Beckert, Jens, and Patrik Aspers, eds. 2011. The Worth of Goods: Valuation and Pricing in the Economy. Oxford: Oxford University Press.

Bowker, Geoffrey C., and Susan Leigh Star. 1999. Sorting Things Out: Classification and Its Consequences. Cambridge, Mass.: MIT Press.

Çaliskan, Koray, and Michel Callon. 2009. "Economization, Part 1: Shifting Attention from the Economy towards Processes of Economization." Economy and Society 38 (3): 369-398.

- 2010. "Economization, Part 2: A Research Programme for the Study of Markets." Economy and Society 39 (1): 1-32. 
Dewey, John. 1939. "Theory of Valuation." In International Encyclopedia of Unified Science 2 (4): 1-67.

Feyerabend, Paul. (1975) 1993. Against Method: Outline of an Anarchistic Theory of Knowledge. Third ed. London: Verso.

Holbrook, Morris B., ed. 1999. Consumer Value: A framework for Analysis and Research. London: Routledge.

Karpik, Lucien. 2010. Valuing the Unique: The Economics of Singularities. Princeton: Princeton University Press.

Knorr Cetina, Karin. 2006. "The Market." Theory, Culture and Society 23 (2-3): 551-556.

Lamont, Michele. 2012. "Toward a Comparative Sociology of Valuation and Evaluation." Annual Review of Sociology 38: 1-21.

Shove, Elizabeth, and Luis Araujo. 2010. "Consumption, Materiality, and Markets." in Reconnecting Marketing to Markets edited by Luis Araujo, John H. Finch and Hans Kjellberg, 13-28. Oxford: Oxford University Press.

Stark, David. 2009. The Sense of Dissonance. Accounts of Worth in Economic Life. Princeton, NJ: Princeton University Press.

Taylor, Paul W. 1961. Normative Discourse. Englewood Cliffs, N.J.: Prentice-Hall.

Hans Kjellberg is associate professor at Stockholm School of Economics. His research interests are in economic ordering and, particularly, the organizing of markets. Over the past decade, he has worked to establish market studies as an interdisciplinary field of inquiry and sought to contribute to a practice approach to markets. Currently, he is engaging in a new collaborative, interdisciplinary project on the digitalization of consumer culture.

Alexandre Mallard, Centre de Sociologie de l'Innovation, Ecole des Mines ParisTech, was trained as an engineer and as a sociologist in the field of Science and Technology Studies (STS). In the past years, his research has focused on the uses of Information and Communication Technology in organizations and markets. He is currently engaged in a project studying the role of labels in the governance of innovation, at the crossroads of economic sociology and public policy. 